\title{
A CRIAÇÃO DE UMA TRADIÇÃO CRÍTICA NA AMÉRICA LATINA E O IMAGINÁRIO DA LITERATURA TRANSFRONTERIC̣A NO SUL DO BRASIL
}

\author{
Cátia Goulart ${ }^{32}$
}

RESUMO: Neste artigo reflito sobre as relações entre a literatura de fronteiras produzida entre o sul do Brasil, Uruguai e Argentina e seu vínculo com a construção de uma linha expressiva do pensamento crítico na América Latina: o paradigma da transcultural. Busco por um lado destacar momentos de articulação desse método de leitura no âmbito da crítica latino-americana; por outro, evidencio como tal paradigma foi a base para uma mudança de perspectiva por parte dos pesquisadores brasileiros dedicados à literatura da região. Destaco um descompasso: a relação entre o corpus e a crítica tem criado um consistente imaginário em torno de uma unidade cultural configurada como cultura gauchesca/ pós-gauchesca, quando a literatura contemporânea produzida por escritores da região lida com um imaginário muito mais diversificado do que a produção crítica tem tratado. Assim, mediante a leitura crítica da crítica, observo a homogeneização do imaginário cultural dessa região, e, considerando a pluralidade da ficção local na contemporaneidade, proponho a desarticulação dessa imagem. Para tanto, retomo o pensamento crítico na América Latina pela perspectiva de leitura que vem sendo concebida como Pensamento de Fronteira e promovo a leitura da ficção local em sua diversidade.

Palavras-chave: imaginários do Sul; pensamento crítico na América Latina; transculturação, literatura de fronteira.

RESUMEN: En este artigo reflexiono sobre las relaciones entre la literatura de fronteras del sur de Brasil, del Uruguay y de la Argentina en su vínculo con la construcción de una línea expresiva del pensamiento crítico en la América Latina: el paradigma de la transculturación. Busco por un lado destacar momentos de articulación de ese método de lectura en el ámbito

\footnotetext{
${ }^{32}$ Doutora em Teoria Literária pela Pontificia Universidade Católica do Rio Grande do Sul, Professora da Universidade Federal do Pampa/UNIPAMPA.

Caderno de Letras, n 26, Jan-Jun - 2016 - ISSN 0102-9576
} 
de la crítica latinoamericana; por otro, evidencio como ese paradigma fue la base para un cambio de perspectiva de investigadores brasileños dedicados a la literatura de la región. Destaco el descompaso: la relación entre el corpus y la crítica ha criado un fuerte imaginario en torno de una unidad cultural configurada como cultura gauchesca/ pósgauchesca, aun cuando la literatura contemporánea producida por escritores de la región trabaja con un imaginario mucho más diversificado. Con la lectura crítica de la crítica, observo la homogeneización del imaginario cultural de la región, y, considerando la pluralidad de la ficción local en la contemporaneidad, propongo la desarticulación de esta imagen. Para eso retomo el pensamiento crítico en la América Latina desde la perspectiva de lectura que es articulada como Pensamiento de Frontera y promuevo la interpretación de la ficción local en su diversidad.

Palabras clave: imaginarios del Sur; pensamiento crítico en la América Latina; transculturación, literatura de frontera.

Geralmente quando nos referimos à literatura do sul do Brasil, em especial aquelas que têm como lócus de enunciação e/ou de produção essa região com as fronteiras do Uruguai e da Argentina, costumamos escutar por parte de nossos interlocutores uma pergunta de cunho retórico: "ah...trabalhas com a literatura gauchesca?"

Esse senso comum sempre me incomodou, não exatamente porque discorde de que há uma produção cultural significativa atuando sobremaneira na construção do imaginário dessa região, mas, sobretudo, porque leitora de uma literatura contemporânea, cujo espaço criativo articula-se com esses referentes geoculturais, convivo com uma pluralidade ficcional que atenta para múltiplas inscrições sociais da região, ou seja, que não se limita à literatura gauchesca.

Converti esse incômodo relativo à perspectiva homogênea com que se percebe/concebe a literatura transfronteriça dessa região, e algumas de minhas dúvidas pertinentes aos fundamentos epistemológicos de tal perspectiva, em objeto de pesquisa. Para isso, lancei-me algumas perguntas que nortearam o início de minha reflexão: a partir de quando e o que teria motivado a crítica no âmbito brasileiro a refletir em torno das relações entre a literatura/cultura da região sul do Brasil com a uruguaia e argentina? A partir de que fundamentos epistemológicos estabelece-se a relação entre o imaginário da crítica e a ficção dessa região cultural, seu objeto de leitura? 
Creio que se as primeiras perguntas possibilitam-me rastrear um percurso de construção de um imaginário crítico em torno da ficção de um espaço mais delimitado e sua inter-relação com tendências da crítica na América Latina; a última permite-me, em especial, pensar a relação entre o objeto de pesquisa e a perspectiva adotada. Por esse viés, quero ponderar acerca dos alcances e limites do imaginário crítico, bem como propor caminhos de leitura que possibilitem maior visibilidade à pluralidade criativa na região, ainda que nesse trabalho eu me volte à cultura letrada, em especial, a literatura.

Enfrentando o primeiro questionamento constato que foi no final dos anos oitenta que muitos pesquisadores brasileiros voltaram-se para a leitura ou releitura de parte significativa da literatura produzida no Rio Grande do Sul em sua relação à literatura produzida no Uruguai e parte da Argentina. Porque, apesar de iniciativas pioneiras nas primeiras décadas do século XX para as relações entre a literatura produzida em parte do Rio Grande do Sul com a literatura da região do Prata ${ }^{33}$, o que preponderou no âmbito da crítica até as últimas décadas do referido século foi, sobretudo, uma perspectiva nacionalista de interpretação dessa produção local, relacionando-a a outros regionalismos no Brasil.

Cabe destacar a relação entre a fundação da Associação Brasileira de Literatura Comparada e a revitalização dos estudos da literatura da região sul, por parte da crítica literária brasileira. $\mathrm{O}$ trabalho precursor de Tania Franco Carvalhal, sobretudo a partir da organização do primeiro Seminário Latino-Americano de Literatura Comparada ${ }^{34}$, e a consequente fundação da Associação Brasileira de Literatura Comparada (1986) são marcos da iniciativa de pensadores brasileiros para o fomento sistemático de uma perspectiva crítica comparatista da literatura na América Latina.

\footnotetext{
${ }^{33}$ Refiro-me aos trabalhos inaugurais de João Pinto da Silva (1924) e Guilhermino César (1956), que apontavam a significativa presença hispânica no povoamento, na história e nas relações culturais da região do sul do Brasil. Tal perspectiva, contudo, não obteve maior atenção por parte da crítica nacional e, no âmbito do estado do Rio Grande do Sul, foi frequentemente negada pela critica predominante.

${ }^{34}$ No âmbito do XI Congresso da Associação Internacional Literatura Comparada, na Place de la Sorbonne, em agosto de 1985, os pesquisadores brasileiros presentes dispuseram-se a sediar o I Seminário Latino-Americano de Literatura Comparada, realizado entre os dias 9 e 10 de setembro de 1986, em Porto Alegre. Dentre as propostas do evento, estava prevista e efetivouse a criação da Associação Brasileira de Literatura Comparada. Dados pesquisados em www.abralic.org.br.
} 
As presenças de expoentes como Ana Pizarro e Antonio Candido na fundação da ABRALIC, associadas aos debates que, na ocasião, se deram sinalizam a abertura dos estudos comparatistas no Brasil para a literatura produzida no continente latino-americano. As palavras de Pizarro por um "comparativismo descolonizado" (PIZARRO, 1986, p. 7), proferidas na ocasião, evidenciam sua sintonia com o pensamento de Candido, quando esse considera que pensar o Brasil e sua relação com a hispano-américa "fundamenta-se em problemas de natureza políticoideológica" ${ }^{35}$

Se a origem do comparativismo no Brasil é marcada pelo confronto difuso entre a literatura das metrópoles europeias e a colônia, no âmbito de uma relação dicotômica e hierárquica ${ }^{36}$, com a institucionalização da disciplina de Literatura Comparada na Universidade de São Paulo, em 1962, por Antonio Candido, inicia-se não só a repensar os métodos de análise, mas também o próprio objeto literário. Contribuições de outras áreas dos estudos linguísticos e literários, como o conceito de texto, de intertextualidade e de recepção foram incorporadas e desenvolvidas pela disciplina, fazendo com que as antigas noções de fonte e influência começassem a ser repensadas.

Foi, sobretudo, com a fundação da ABRALIC, no entanto, como sinalizaria Carvalhal anos mais tarde, que se deu a sistematização de posições teóricas e metodológicas dos estudos comparatistas praticados em distintas universidades brasileiras. Além disso, em um plano mais geral, a proposta da Associação "apontava para a construção de um novo objeto teórico constituido das diversas literaturas nacionais do continente" (CARVALHAL, 1996, p. 4).

Em sintonia e afastamento com a perspectiva comparatista anunciada por Carvalhal, a crítica no Brasil, assumiu vários rumos. Um

\footnotetext{
35 Já na obra Literatura latinoamericana como proceso, organizado por Pizarro em 1985, no capitulo intitulado "Exposición de Antonio Candido", o critico brasileiro manifestava que “... en este equipo debemos insistir en incluir el Brasil, no solamente para completar el panorama, sino también por motivos de naturaleza político-ideológico, en el sentido más amplio..." (PIZARRO, 1985, p.78).

${ }^{36}$ Wander Miranda e Eneida Souza, ao traçarem um histórico do comparativismo no Brasil, destacam que iniciativas comparatistas podem ser vistas já no periodo romântico, no afã de afirmar uma literatura nacional frente à portuguesa. Contudo, para eles, as primeiras experiências significativas da área são as empreendidas por Eugenio Gomes, Augusto Meyer e Otto Maria Carpeaux, entre as décadas de 1940 e 1950. SOUZA, Eneida; MIRANDA, Wander. Perspectiva da Literatura Comparada no Brasil. In: CARVALHAL, Tania Franco (org.). Literatura comparada no mundo: questões e métodos. Porto Alegre: L\&PM/VITAE/AILC, 1997, p. 40.
} 
deles, que aqui enfoco, foi o da releitura da literatura da região sul do Brasil.

Nesse processo, o pensamento crítico de Angel Rama foi basilar. Rama, articulando e desenvolvendo diferentes conceitos, não só precedentes da América Latina ${ }^{37}$, mas também da Europa ${ }^{38}$, promove um olhar crítico complexo, pois, sem desconsiderar o interior do espaço, da história e do imaginário da nação, nem tampouco seus vínculos com as metrópoles, entende as relações de contato cultural para além desses limites, ao propor uma leitura a partir de "comarcas culturais". Assim, para além das noções hegemônicas de nação, a concepção de "comarca cultural" proposta por Rama sinaliza um olhar mobilizador da transitividade entre a cultura de várias nações cujas regiões são reconhecidas em seus valores, crenças, experiências culturais e estéticas similares.

Tal perspectiva de estudos destacada pelo crítico uruguaio, acerca da possibilidade de se pensar a multiplicidade de registro do continente, a diversidade no interior da própria nação e os vínculos culturais de regiões para além dos limites e/ou continuidades das nações instituídas apontam novos horizontes para os estudos comparatistas na América Latina. ${ }^{39}$

Mas além do conceito de comarca cultural que possibilitou pensar novos recortes e delimitações da produção cultura como objetos de leitura por parte da crítica, outra contribuição fundamental advém da proposta metodológica de interpretação que Rama articula: a elaboração de um método de leitura que ele denominou transculturación narrativa.

\footnotetext{
${ }^{37} \mathrm{O}$ pensamento de Angel Rama conta com um diálogo com reflexões teóricas de diferentes intelectuais da América Latina e inaugura um paradigma epistemológico para leitura da cultura, em especial da literatura na década de oitenta, tradição que conta com, além do pensamento de Fernando Ortiz (1944), de críticos como Pedro Henriquez Ureña, Picón Salas, Gilberto Freire, Darcy Ribeiro, Antonio Candido. Importante destacar também o papel da Biblioteca Ayacucho, na Venezuela, dirigida por Ángel Rama, onde ele leu, publicou, divulgou e aproximou-se de muitos escritores latino-americanos. Essa expressiva linha de tradição de pensamento na América Latina cuja base é o paradigma articulado por Rama é tratado em minha tese.

38 Para uma abordagem acerca da influência da Escola de Frankfurt e do Marxismo no pensamento de Rama, ver a entrevista concedida por ele a Jesús Díaz Caballero: Ángel Rama o la critica de la transculturación (Una entrevista). In: MORANÃ, Mabel (org.). Ángel Rama y los estudios latinoamericanos. Pittsburg: Instituto Internacional de Literatura Iberoamericana, 1997.

${ }^{39}$ Em relação a esse tópico vale considerar a apreciação de Eduardo Coutinho acerca da importância dos estudos comparados na América Latina. Ver: Coutinho, Eduardo. Sentido e função da Literatura Comparada na América Latina. In: Literatura Comparada na América Latina - Ensaios. Rio de Janeiro: Eduerj, 2003, p. 11-29.
} 
Desde meados dos anos setenta, Rama retoma o conceito de transculturação concebido pelo antropólogo cubano Fernando Ortiz $(1940)^{40}$ e adapta-o à leitura da literatura na América Latina. É realizando uma leitura de obras de diferentes ficcionistas que Rama desenvolve sua proposta de método interpretativo da cultura latino-americana. Se no artigo Los procesos de transculturación en la narrativa latino-americana (1974) Rama já apontava a importância do conceito para a copreensão da literatura latino-americana é, especialmente, em Transculturación narrativa en América Latina (1982), que ele desenvolveria o conceito. Entendendo que os escritores retomam múltiplas e conflituosas vozes da cultura para gerar uma literatura própria, Rama propõe um estudo desse processo a partir de três dimensões: os assuntos, a cosmovisão e as formas literárias. Considerando essas estratégias narrativas, o crítico considera que

...pérdidas, selecciones, redescubrimientos e incorporaciones: Estas cuatro operaciones son concomitantes y se resuelven todas dentro de una reestructuración general del sistema cultural, que es la función creadora más alta que se cumple en un proceso transculturante (RAMA, 1982, p. 39).

O conceito em sua acepção original, sua adaptação por Rama, bem como seus desdobramentos no âmbito da crítica literária e migrações para diferentes áreas de estudo, revelam uma expressiva linha do pensamento crítico na América Latina e têm sido alvo de diferentes apreciações críticas ao longo de sua história. Eu, nesse trabalho, limito-me a refletir sobre sua inserção no âmbito cultural brasileira e, em especial, sua relação com a criação do imaginário de uma área cultural específica do Cone Sul.

\footnotetext{
${ }^{40}$ Fernando Ortiz, em sua obra Contrapunteo cubano del tabaco y el azúcar (1940), desenvolve o conceito de transculturación como um rico processo em que diferentes culturas fundem-se, criando novos fenômenos culturais. Retomando o texto original de Ortiz "El vocablo transculturación expresa mejor las diferentes fases del proceso transitivo de una cultura a otra, porque éste no consiste solamente en adquirir una distinta cultura, que es lo que en rigor indica la voz angloamericana acculturation, sino que el proceso implica también necesariamente la pérdida o desarraigo de una cultura precedente, lo que pudiera decirse una parcial deculturación, y, además, significa la consiguiente creación de nuevos fenómenos culturales que pudieran denominarse de neoculturación. Al fin, como bien sostiene la escuela de Malinowski, en todo abrazo de culturas sucede lo que en la cópula genética de los individuos: la criatura siempre tiene algo de ambos progenitores, pero tambiénsiempre es distinta de cada uno de los dos. En conjunto, el proceso es una transculturación, y este vocablo comprende todas las fases de su parábola" (ORTIZ, 1940, p. 142).
} 
Nesse sentido, primeiramente destaco que a aproximação do crítico uruguaio, em especial, com dois intelectuais brasileiros - Darcy Ribeiro e Antonio Candido - favoreceu a retomada e a articulação de conceitos, bem como a ampliação de reflexões desenvolvidas por Rama, como aponta recentemente Flávio Aguiar. ${ }^{41} \mathrm{E}$, sobretudo favoreceu que o paradigma transculturador promovido por Rama, fosse tomado como categoria de interpretação não somente da literatura, mas da cultura latino-americana de modo geral, por pesquisadores brasileiros.

Ao que se refere ao Brasil, interessa-me, sobretudo, os estudos delimitados em torno do que Rama delineou como "comarca literária do pampa".

Buscando refletir sobre a inter-relação dessa expressiva linha do pensamento crítico na América latina em relação à interpretação de uma região específica, destaco que, já em trabalhos anteriores ${ }^{42}$, Ángel Rama, especialmente em seus estudos relacionados à gauchesca, desenvolve a base para a adaptação da ideia de transculturação, ao pensar essa região, o que mais tarde ele ampliaria, em Transculturación narrativa en América Latina, tornando-a categoria central em seu pensamento crítico.

É certo que o desafio de pensar o objeto - América Latina e sua cultura - desde reflexões críticas que reconheçam e tensionem o espaço intervalar entre o local e o global, foi o elemento-chave para a articulação e o desenvolvimento do pensamento latino-americano, especialmente a partir da década de sessenta, por parte de muitos pesquisadores. Uma das respostas mais concretas no campo da crítica e da história da literatura, pode ser vista pela publicação de América Latina en su literatura (1972), que organizada por César Fernandez Moreno, evidencia um dos marcos resultantes dessa iniciativa integradora. Outro foi uma série de encontros, debates e reuniões de intelectuais e escritores de diferentes países, entre eles Antonio Candido, Ángel Rama, Jacques Leenhardt, Beatriz Sarlo, Roberto

${ }^{41}$ AGUIAR, Flávio. Ángel Rama e Antonio Candido - de um encontro feliz a uma nova realidade critica na América Latina. In: AGUIAR, Flávio; RODRIGUES, Joana. Ángel Rama: um transculturador do futuro. Belo Horizonte: Ed. UFMG, 2013, p. 33-45.

${ }^{42}$ Em, por exemplo, Los gauchipolíticos rioplantenses (1976), o sistema em foco, objeto de sua leitura, está duplamente indiciado já no titulo. Rama compõe a obra a partir da junção de um conjunto de artigos, cujo centro de reflexão se dá em torno da literatura tradicional, limitandose, no entanto, a tratar da gauchesca, a partir da literatura na Argentina e no Uruguai. É somente em ampliação desse sistema literário para a inclusão da região sul do Brasil, como bem acentuaria Transculturación narrativa en América Latina, em que ele viria a propor a relevância da relação entre literatura e tradição cultural a que um texto pertence. 
Schwartz, Cornejo Polar, Roberto Fernandez Retamar, os quais resultam nas obras La literatura latinoamericana como proceso (1985) ${ }^{43}$, Hacia una historia de la literatura latinoamericana (1987), organizadas por Ana Pizarro, todas com o apoio da UNESCO e essas duas últimas também com o da Associação Internacional de Literatura Comparada. O empreendimento, agregando também outros pensadores, converge na produção da antologia crítica intitulada América Latina, Palavra, Literatura e Cultura, igualmente organizada por Pizarro, em três volumes, entre 1993 e 1995.

Do conjunto das obras citadas, parece-me oportuno destacar o texto de introdução à Palavra, Literatura e Cultura na América Latina (1993), escrito por Ana Pizarro porque ele se refere, no contexto dos estudos latinoamericanos, uma vez mais a importância, dos estudos da região cultural a que aqui me dedico.

Nesse texto introdutório, a pesquisadora, ao tratar da formação do cânone colonial no novo mundo, apontava que o surgimento das literaturas em relação gera fronteiras culturais. E sublinha, por isso, no caso da América Latina, a necessidade de reconfigurar o cânone a partir de uma perspectiva comparada. Afinal, para Pizarro, a dominação e a submissão forjaram um cânone literário com base no modelo peninsular, que excluiu toda possibilidade de alteridade. Assim, ao questioná-lo, muitas pesquisas e seus consequentes resultados poderiam colocar em evidência, dizia Pizarro, a incompletude do cânone e sua necessidade de revisão, a qual não poderia mais prescindir do corpus ausente, e nesse deveria ser considerado também outras produções simbólicas, para além da letra. Momento, em que ao voltar-se para a literatura brasileira e em certa consonância como paradigma de leitura de Rama, a autora chamou atenção para o fato de que houve, por razões diferentes, uma omissão da tradição luso-brasileira em favor da hegemonia de um corpus hispano-americano na configuração de uma literatura latino-americana. A afirmação é exemplificada, por ela, com a inexistência, entre os trabalhos que foram incorporados ao livro antes citado, de estudos relativos às inter-relações culturais do universo do sul norte da Argentina, sul do Brasil e Uruguai.

Essa carência de estudos apontada por Pizarro (1993), a que Rama (1982) havia se referido, não passa despercebido por pesquisadores brasileiros que já se dedicavam à literatura da região. Nesse caminho é interessante acompanharmos, dentre outros exemplos possiveis, os estudos

43 Ver: ANAIS DO $1^{\circ}$. SEMINÁRIO LATINO-AMERICANO DE LITERATURA COMPARADA. Porto Alegre: UFRGS, 1986. 3v. 
de Ligia Chiappini (USP) e Léa Masina (UFRGS), não só porque elas se dedicam a mais de 40 anos à interpretação dessa região cultural, mas também porque foram orientandas de Candido e de Carvalhal, respectivamente.

Antes, contudo, observo que além da fundação da ABRALIC, que potencializou a circulação de conceitos e metodologias que vinham já sendo articuladas no âmbito do pensamento crítico latino-americano pelo menos desde os anos sessenta, outro fator motivador para a mudança de perspectiva de pesquisa acerca da cultura desenvolvida no sul do Brasil em sua relação com a dos países vizinhos - e não com menor importância - é a criação do Mercosul ${ }^{44}$. Os múltiplos discursos, iniciativas e realizações tanto no campo da política quanto no campo das academias e da produção artística desde então se empenham por promover convênios, estreitar laços culturais e promover reflexões acerca do potencial e limites dessa integração.

Nesse sentido, convém atentarmos para textos de apresentação de livros publicados decorrentes de uma série de eventos, de propostas individuais de pesquisas, de criação de institutos de pesquisa por parte de comunidades acadêmicas e de atividades entre artistas e ativistas culturais ${ }^{45}$ que refletem sobre o potencial das relações inter-culturais e o Mercosul. E inclusive, cabe observar, por parte do governo brasileiro, a criação de universidades em região de fronteiras com os demais paises que integram o Bloco. ${ }^{46}$ Ações que em seu conjunto fomentam e justificam

\footnotetext{
${ }^{44}$ Lembremos que se os esforços pelo processo de integração de ordem fundamentalmente comercial percorrem toda década de oitenta, foi em março de 1991 que se efetivou a fundação do Mercosul com a assinatura do Tratado de Assunção, no Paraguai. Mas seria apenas em dezembro daquele ano que os ministros de Educação dos paises-membros do Mercosul, reunidos em Brasilia, pela primeira vez apresentam programas de ação que deveriam ser desenvolvidos em projetos educacionais no âmbito do bloco: a formação de consciência social favorável ao processo de integração, a capacitação de recursos humanos e a integração dos sistemas educacionais. Ver: http://www.mercosul.gov.br/.

45 Dentre as primeiras ações politicos-culturais realizadas ao calor da fundação do Mercosul destaco o encontro entre escritores, bailarinas, artistas plásticos ativistas culturais e acadêmicos denominado Diálogo cultural latino-americano, ocorrido ainda em 1991, em Porto Alegre. Ver livro. CEBALLOS, Jose Gabriel e NAPP, Sergio. Marcosul/MarcoSur. Porto Alegre: Tchê!, 1992.

${ }^{46} \mathrm{Na}$ região sul destaco, dentre outras iniciativas, a criação de três Universidades Federais: a Universidade Federal do Pampa (UNIPAMPA 2006/2008), Universidade Federal da Fronteira Sul (UFFS 2007/2009) e, em especial, a Universidade Federal da Integração LatinoAmericana (UNILA - 2007/2010).
} 
constantemente a potencialidade dessa associação. Para maiores reflexões críticas em torno desse tema é interessante recorrer a trabalhos de pesquisadores como os argentinos Albert Methol Férré (1991), Santiago Kovadlof (1997), Alejandro Grimson (2001), do uruguaio Jorge Carlos Guerrero (2010), convergentes em suas avaliações no sentido de destacar que a partir dos anos noventa a maior expressão do empenho integracionista latino-americana tem sido o Mercosul.

No entanto, considerando os limites desse artigo e meus objetivos anteriormente traçados, centro-me em alguns dos principais trabalhos de Ligia Chiappini ${ }^{47}$, a fim de refletir sobre seus percursos, seus fundamentos teóricos e atuação no imaginário crítico sobre a região.

Chiappini é uma pesquisadora que desenvolve ao longo de toda a sua trajetória acadêmica um trabalho acerca da literatura da região sul. Inicialmente, suas pesquisas, sob a orientação de Antonio Candido, dedicam-se à revisão da literatura regional do Rio Grande do Sul em sua relação com o modernismo no Brasil. Do estudo em questão, resultou a obra Modernismo no Rio Grande do Sul: materiais para o seu estudo (1972).

A perspectiva adotada tem seguimento em seu doutorado, também sob a orientação de Candido, centrando-se, porém, na leitura crítica de poesia, de narrativa e de ensaios, com o objetivo de investigar a tensão estabelecida entre modernismo e regionalismo no sul do país. Parte do referido estudo resulta na obra Regionalismo e Modernismo: o caso gaúcho (1978), na qual, a partir da leitura de nove narrativas ficcionais ${ }^{48}$, a autora avalia a existência de uma dissonância entre a posição propalada pela ensaística do sul, por uma originalidade e experimentação formal, o que a vincularia à estética modernista, e a produção ficcional da região. Salvaguarda, contudo, a obra de João Simões Lopes Neto, uma vez que para ela, a "interiorização do foco narrativo" como técnica que absorve e valoriza a fala do outro, a do peão da estância, fez de Lopes Neto um precursor do modernismo no sul. Destaca já naquele momento os vínculos desse escritor com a região do Prata, uma vez que sua narrativa incorpora não só

\footnotetext{
${ }^{47} \mathrm{Um}$ estudo mais extensivo do percurso das duas pesquisadoras pode ser acompanhado no primeiro capitulo de minha tese de doutorado, intitulada Imaginários do Sul: pensamento crítico de fronteira e os avessos da modernidade em Aldyr Garcia Schlee, <http://repositorio.pucrs.br/dspace/handle/10923/8361>.

${ }^{48}$ Os titulos estudados por Chiappini abarcam narrativas das primeiras décadas do século XX e são: Contos Gauchescos (1912) e Casos de Romualdo (1914), ambos de Simões Lopes Neto; Alma bárbara, de Alcides Maya (1922) e Querência, de Vieira Pires; No pago, de Clemêncio Barnasque; Pampa, de João Maia, No galpão, de Darcy Azambuja, todas de 1925, e Quero-quero, de Roque Callage (1927).
} 
expressões e palavras em espanhol, mas também fontes historiográficas, mitos e lendas registradas em livros de estudiosos rio-prantenses.

Tal perspectiva teve continuidade em sua tese de livre-docência ${ }^{49}$, momento em que ela retoma parte de suas investigações desenvolvidas no doutorado e empreende uma profunda reflexão sobre a obra de Simões Lopes Neto. Esse trabalho resulta na obra No entretanto dos tempos: literatura e história em Simões Lopes Neto (1988) e na edição crítica da obra de Simões Lopes Neto, que Chiappini preparou no mesmo ano ${ }^{50}$.

Entre 1989 e 1993, a pesquisadora volta-se ao estudo da questão do regionalismo na Europa. Neste processo, a pesquisadora prepara um balanço teórico que acaba por sintetizar no texto "Do beco ao belo: dez teses sobre o regionalismo na literatura". (1994) $)^{51}$ As teses oferecem um panorama histórico do regionalismo no Brasil e na Europa, destacam alguns momentos significativos da tendência do século XIX aos anos noventa do século XX e acentuam o caráter político, cultural e estético das obras. No mesmo ano, Chiappini havia publicado o texto "Velha praga? Regionalismo literário brasileiro", junto à obra Palavra, Cultura e Literatura na América Latina, organizada por Ana Pizarro ${ }^{52}$, onde tratava da mobilidade dessa tendência literária ao longo da história da literatura brasileira. Se já nesse artigo ela sugere que a relação entre subdesenvolvimento e produção ficcional não é suficiente para se entender o "fôlego de gato" do regionalismo no Brasil e na América Latina como um todo, em suas teses, a pesquisadora reafirma a questão. A ampliação de seus estudos pela Europa levou-a a "repensar a tese bastante aceita pela crítica brasileira de que o problema do regionalismo seria decorrência do

\footnotetext{
49 Iniciando um estágio de pesquisa junto ao Instituto de Estudos Latino-Americanos, na Universidade Livre de Berlim, Alemanha - onde posteriormente atuaria como docente -, Chiappini realiza, em diferentes paises da Europa, um levantamento bibliográfico sobre estudos do regionalismo.

${ }^{50}$ Ver: Contos gauchescos, Lendas do sul e Casos do Romualdo, edição, apresentação e notas de Ligia Chiappini. Rio de Janeiro: Ed Presença-INL, 1988.

${ }^{51}$ Este artigo, publicado primeiramente nas Atas do Congresso de Literaturas Lusófonas, realizado em Lisboa, em 1994, foi posteriormente publicado no Brasil. Ver: CHIAPPINI, Ligia. Do beco ao belo: dez teses sobre o regionalismo na literatura. Estudos Históricos, Rio de Janeiro, vol. 8, n. 15, 1995, p. 153-159.

${ }^{52}$ Obra citada, p. 665-702.
} 
subdesenvolvimento e, como tal, irrelevante nos países do primeiro mundo..." (CHIAPPINI, 2012, p. 10)..$^{53}$

No que se refere aos seus estudos da ficção produzida no Rio Grande do Sul, Chiappini seguia, predominantemente, situando-o no campo da literatura nacional. Contudo, no final dos anos noventa a pesquisadora movimenta-se, paralelamente, em duas direções que se entrecruzam: por um lado, aprofunda seus estudos dos regionalismos no Brasil e da literatura urbana, a partir das relações entre literatura e história ${ }^{54}$; por outro, se abre à literatura do Prata.

Buscando ater-me ao foco de minhas reflexões, destaco, neste momento, alguns de seus trabalhos acerca do segundo viés aqui apontado.

Seu artigo "De Fausto a Fausto, o gaúcho na ópera" (2000), leitura realizada acerca da obra de Estanislao del Campo, aponta uma ampliação do estudo da literatura gauchesca por parte da pesquisadora, já que ela se volta para a leitura de textos produzidos por hispanoamericanos. Também seu artigo "Martín Fierro e a cultura gaúcha do Brasil", integrante da edição crítica do texto de José Hernandez, editado pelos argentinos Élida Lois e Ángel Nuñez, em 2001, é mais um exemplo da ampliação da perspectiva de leitura do regional, por parte de Chiappini. Nesse texto, a pesquisadora empreende um estudo das traduções de Martín Fierro no Brasil, considerando especialmente sua recepção por poetas, escritores e pela crítica literária. Chiappini retoma e amplia a publicação do mencionado trabalho no artigo "Martín Fierro é brasileiro?" (2004) $)^{55}$, no qual, ao tratar do debate e da construção da narrativa em torno da importância dessa obra de Hernandez na cultura do Rio Grande do Sul, a autora compara duas traduções realizadas para o português da primeira parte de Martín Fierro, "A Ida".

Além de ampliar seu objeto de estudo para a ficção e para obras da região sul, de cultura hispânica, Chiappini paralelamente reflete, em diálogo com historiadores, acerca da construção das fronteiras. Tal

\footnotetext{
${ }^{53}$ Fragmento do Texto Regionalismo(s) e Regionalidade(s) num mundo supostamente global, apresentado na ABRALIC, em 2012. Recebi da autora, por email, no dia 18 de agosto de 2014; a paginação está de acordo com o texto enviado por Chiappini.

${ }^{54} \mathrm{O}$ momento inicial de reflexões entre história e ficção na América Latina, na obra de Chiappini, pode ser percebido na constituição do grupo de pesquisa Angel Rama, criado junto ao Centro Interdepartamental na Faculdade de Filosofia, Letras e Ciências Humanas da USP, conforme relato de pesquisas do grupo, apresentado por Chiappini, no II Congresso da ABRALIC, 1990. Ver: ANAIS.

${ }^{55}$ Artigo publicado na obra Pampa e Cultura de Fierro a Netto, organizada por Ligia Chiappini, Maria Helena Martins \& Sandra Pesavento. Porto Alegre: Editora da UFRGS, 2004.
} 
empreendimento pode ser acompanhado tanto por sua participação no Encontro da Associação Nacional de Pesquisadores em História (1999) quanto por seu artigo, apresentado na ocasião, "Relações entre História e Literatura no contexto das humanidades hoje: perplexidades" (2000). Também na organização do livro Literatura e cultura no Brasil: identidades e fronteiras (2002), que realizaria junto com Maria Stellla Brescianni, como resultado de um encontro de literatos e historiadores em Varsóvia, também em 2002. E ainda nos estudos da pesquisadora, relativos à obra de Cyro Martins, José Lins do Rego, Graciliano Ramos, Rachel de Queirós e Erico Verissimo, apresentados em diferentes eventos.

Sua mudança de perspectiva, contudo, é exposta de modo mais orgânico no artigo "O modernismo no Rio Grande do Sul: revisitando uma pesquisa dos anos setenta", publicado na revista Literatura e Sociedade (2003/2004). No texto citado, Chiappini reavalia suas pesquisas dos anos setenta e rediscute alguns pressupostos, refletindo acerca da pertinência de se repensar a relação entre modernismo e regionalismo nos momentos atuais. Ela pondera, enfim, que, apesar de manter muitas das considerações feitas a partir de suas pesquisas e apontadas em obras anteriores, a produção gaúcha, graças ao seu regionalismo, "pode manter uma certa originalidade em relação às influências do centro, coerentemente com sua cultura particular e com o estágio de desenvolvimento da sociedade gaúcha da época" (CHIAPPINI, 2004, p. 264).

Por isso, ela considera o caso gaúcho exemplar para se refletir sobre modernidades plurais e para se repensar as relações entre nação, região e mundo, bem como localismos e cosmopolitismo, vanguarda e regionalismo.

E especialmente em sua pesquisa Fronteiras culturais e cultura fronteiriça na comarca pampeana: obras exemplares, iniciada em 2004, financiada pelo Programa Internacional Brasil-Alemanha (PROBRAL), que Chiappini se propõe a atualizar o tema da literatura e cultura gaúcha e gaucha em tempos de globalização. Para tanto, empreende, desde uma abordagem comparativa, uma leitura de textos brasileiros, argentinos e uruguaios, considerados exemplos da tensão nacional, regional, transnacional nos séculos XIX e XX.

Nessa pesquisa de fôlego, Chiappini parte de um questionamento em torno das identidades nacionais e regionais da comarca pampiana e do papel dos textos literários nesse processo. Dentre os objetivos do projeto, está a intenção de "Apresentar a gauchesca como sistema literário 
transnacional, sob uma nova luz, especialmente exemplar de uma cultura de fronteira" (CHIAPPINI, 2004, p. 259).

O trabalho em andamento e as obras resultantes de sua trajetória de investigações, das orientações de pesquisa em âmbito de graduação, mestrado, doutorado e pós-doutorado em universidades brasileiras e fora do Brasil, somados às articulações de Chiappini com investigadores/pesquisadores no Brasil, na América hispânica e na Alemanha, tornam evidente a dedicação da pesquisadora ao estudo da comarca pampiana. ${ }^{56}$

$O$ projeto que coordena, conforme ela mesma apresenta na obra Pampa e Cultura: de Fierro a Netto (2004), desenvolve-se a partir de três linhas de pesquisas: as duas primeiras são trabalhadas autonomamente, enquanto a terceira, de modo transversal a elas. A primeira linha organizase em torno da "Formação das literaturas nacionais como criação das fronteiras culturais"; a segunda focaliza "O gaúcho como figura fronteiriça: morte e ressurreição"; e a terceira, "Fronteiras linguísticas: mesclas e delimitações, do léxico à pragmática”.

Partindo do conceito de Benedict Anderson, de nação enquanto comunidade imaginada (1983), Chiappini, em suas reflexões acerca das literaturas nacionais da região sul da América - Argentina, Uruguai e Brasil -, quer considerar "a diversidade e pluralidade das culturas regionais" (CHIAPINNI, 2004, p. 253), tanto nas dimensões nacionais quanto na condição transnacional em que cultura e a ficção vêm sendo construídas.

Com essa perspectiva, os estudos sob sua coordenação cobrem um amplo arco temporal: da segunda metade do século XVIII ao final do século

\footnotetext{
${ }^{56}$ No Apêndice da obra Pampa e Cultura, intitulado "Projetos Fronteiriços", Ligia Chiappini apresenta seu projeto "Fronteiras culturais e cultura fronteiriça na comarca pampeana: obras exemplares", proposto em parceria entre a Universidade Livre de Berlim e a Universidade de São Paulo, sendo coordenado por ela e por Sandra Nitrini. Evidencia ainda que o projeto, articulado ao Programa de Pesquisa do Instituto Latino-Americano da Universidade Livre de Berlim, tem buscado integrar pesquisadores autônomos ou membros de equipes institucionais que se dedicam à temática de fronteiras. Dentre os projetos, ela aponta o desenvolvido por Ana Pizarro sobre a região amazônica e, em especial, os projetos que tratam da comarca pampeana. Nesse caso, Chiappini destaca o intercâmbio com o projeto Fronteiras Culturais (Brasil-Uruguai-Argentina), coordenado por Maria Helena Martins, diretora do Centro de Estudos de Literatura e Psicanálise Cyro Martins. Tais projetos congregam Léa Masina, professora da Universidade Federal do Rio Grande do Sul; Pablo Rocca, professor da Universidad de la República, Uruguai, e os professores argentinos Élida Lois e Ángel Nuñez; articulam-se ainda a projetos afins, como os iniciados pelos historiadores brasileiros Sandra Pesavento e Serge Gruzinski, que também eram professores da UFRGS e pesquisadores das áreas de ciências sociais do Instituto Ibero-Americano de Berlim.
} 
$\mathrm{XX}$, considerando um conjunto ficcional cujo centro é a figura do gaúcho. Nesse sentido, recorre ao que denomina "de obras exemplares dessa problemática nacional, regional e fronteiriça, que se tece, sobretudo, em torno da figura do gaúcho" (CHIAPPINI, 2004, p. 254).

Partindo da delimitação estabelecida, a seleção do corpus prevê não apenas obras clássicas da literatura gauchesca, mas também a inclusão de textos ficcionais que realizam releituras do repertório em questão. A postura de incluir em seu recorte a leitura de obras que dialogam e desconstroem a gauchesca, deve-se ao fato de que Chiappini reconhece nelas uma continuidade do gênero e, por sua vez, que as mesmas podem ser integradas ao que o uruguaio Pablo Rocca (2004) entende como uma pós-gauchesca.

A pesquisadora alerta para o fato de que a literatura do Rio Grande do Sul tanto quanto a argentina e a uruguaia estão relativamente bemestudadas, contudo, considerando as aproximações existentes entre esses países, "O que está pouco estudado é a relação entre elas". (CHIAPPINI, 2004, p. 255). Nesse sentido, ela se propõe a desenvolver estudos comparatistas horizontais sul-sul e, assim, não só superar o desconhecimento entre países com história e culturas afins, mas também retomando um princípio do historiador argentino, Ignácio Corona (1988), para "descolonizar nossa história". 57

Chiappini chama atenção ainda para as transformações da gauchesca, uma vez que se observa recorrência de seus símbolos para além de textos verbais, como nos cinematográficos, pictóricos e musicais, o que exige estudos que também contemplem essas migrações no âmbito da cultura.

No ano de 2004 realiza-se ainda o Simpósio Internacional Fronteiras Culturais no Cone Sul, organizado pelo Centro de Estudos de Literatura e Psicanálise Cyro Martins - CELPCYRO - e pela Cátedra de Literatura e Cultura Brasileira do Instituto Latino-Americano da Universidade Livre de Berlim, em Porto Alegre. Do encontro, resulta a obra Cone Sul - fluxos, representações e recepções (2006), a qual reúne parte das pesquisas realizadas por integrantes dos projetos coordenados pelas organizadoras do evento, bem como por outros convidados, que tratam de expor e debater acerca da circulação, dos intercâmbios e também

57 Chiappini, ao abordar conceito de descolonização, refere-se a reflexões de Ignácio Corona em seu artigo Vecinos distantes? Las agendas criticas posmodernas en hispanoamerica y el Brasil. Revista iberoamericana. Vol. LXIV. Núms 182-183, Enero-Junio, 1998, p. 17-38. 
dos cerceamentos e enfrentamentos de pessoas, mercadorias, ideias, línguas, artes, símbolos e modos de interpretá-los no contexto de um Mercosul cultural.

No conjunto dos trabalhos que integram a obra, está o artigo "João Simões Lopes Neto e Javier de Viana: dois escritores fronteiriços e um diálogo hipotético", de Chiappini. Nele, a pesquisadora reitera parte dos objetivos de seu projeto, entre eles o de:

Retomar os estudos de Ángel Rama (1967 e 1985) e Alejandro Losada (1976), de Guilhermino César (19561973), Manoelito de Ornellas (1948), Augusto Meyer (1952) e Donaldo Schüller (1987) para citar os mais importantes entre os que tentaram algumas comparações entre a gauchesca brasileira e a platina, desenvolvendo e aprofundando hipóteses e intuições que eles apenas formularam (CHIAPPINI, 2006, p. 72).

Por entender que estudar o regionalismo na fronteira sul do Brasil com os países do Prata é repensar as identidades híbridas que aí se configuraram e reconfiguram em tempos de globalização, a pesquisadora coloca a necessidade de retomar os fundamentos dos primeiros críticos que trataram do tema. Segundo Chiappini, a literatura da região, no século XX, pode ser compreendida em três momentos: o que abarca as três primeiras décadas, quando se localizam tensões entre pré-modernismo e modernismo; regionalismo e vanguardas; um segundo, situado nas três décadas posteriores e que, atento ao subdesenvolvimento, realiza um neorrealismo crítico e pode ser entendido, no âmbito brasileiro, como um "super-regionalismo"; e um terceiro momento, localizado nas quatro últimas décadas, quando tipos e temas reaparecem, sobretudo, em textos paródicos e acabam sendo incorporados também por outras linguagens, como a música, a telenovela e o cinema.

Encerrando a retomada dos estudos de Chiappini acerca da literatura da região da fronteira no Cone Sul, destaco que tive oportunidade de acompanhar a apresentação de um dos resultados do projeto de pesquisa Mercosul/Mercosur dimensões culturais, politicas e econômicas, um projeto de integração a partir das fronteiras, em 2011, em Porto Alegre. O livro Fronteiras da integração: dimensões culturais do Mercosul = Fronteras de la integración: las dimensiones culturales del Mercosur, organizado por Carla Gallinati, é um dos resultados de pesquisa 
de campo e bibliográfica sobre e na região das fronteiras do Brasil com o Uruguai, a Argentina e o Paraguai, acerca da dimensão cultural do Mercosul, vivenciado por estudantes e professores alemães e brasileiros. ${ }^{58}$

Dentre os artigos apresentados, destaco "Literatura e Fronteiras Culturais: Pampa e Amazônia", de Chiappini. Nele, a pesquisadora expõe a abertura de suas investigações para além da comarca pampiana, conforme já assinala o título do artigo. Mediante a expansão do Mercosul, com o ingresso da Venezuela, e apostando na dimensão social e cultural do bloco, Chiappini destaca a pertinência da ampliação das fronteiras e das áreas culturais a serem estudadas.

Assim, retomando o conceito de comarcas culturais, de Ángel Rama, a fim de entender as culturas que se realizam em espaços transnacionais, ela se dedica, no artigo citado, a tratar de duas comarcas: a pampiana e a amazônica. Observa que a distância e as diferenças topográficas, históricas e culturais entre os dois polos não impedem que se reconheçam semelhanças entre ambas as comarcas. Chiappini, então, reconhece e elenca elementos comuns entre as diferentes comarcas, tais como: a condição de constituírem territórios de passagem e também limites da soberania nacional; a distância que ambos têm do poder central, os processos tardios de incorporação e os conflitos armados que levaram à criação de repúblicas independentes (República de Piratini, 1835/45 e República dos Cabanos, 1830/35); e, finalmente, preocupações de ordem identitária, uma vez que "nas duas comarcas, há uma parte do Brasil oscilando entre ser brasileiro ou ser outro, tensão que deixa rastro até hoje..." (CHIAPPINI, 2011, p. 400).

Por isso, para a pesquisadora, trabalhar com o conceito de comarca cultural, articulando-o ao de América Latina, "implica superar a concepção estática dos territórios e nações para repensá-los não somente como processo e construção, mas, sobretudo, como projeto e utopia a construir pelo trabalho..." (CHIAPPINI, 2011, p. 399).

Com relação ao artigo destacado, limito-me a retomar as principais considerações da pesquisadora acerca dos estudos realizados da ficção narrativa na comarca pampiana, foco de meu interesse.

Reconhecendo que a literatura colaborou muito na reprodução do sistema colonizador, mas também atuou no contraponto da ideologia das

\footnotetext{
${ }^{58}$ Para mais conhecimento sobre o projeto e seus resultados, ver a apresentação do livro, denominada "Crônica de uma experiência", de autoria de Ligia Chiappini e Jan Davidi Hauck (p. 11-19).
} 
cidades letradas, Chiappini, nos interstícios da ficção, considera que outros Brasis aparecem. No caso do pampa, ela reconhece a existência de "diversas faces dessa fronteira-sul" (CHIAPPINI, 2011, p. 404). Entre os exemplos citados pela pesquisadora, encontram-se textos que, ao tratarem da Revolução Farroupilha, ou da Guerra do Paraguai, trazem nas contradições e limites desse momento, o destronamento do gauchismo heroicizante, a tragédia dos negros escravizados ou do peão-soldado, em narrativas como o Neto perde sua alma, de Tabajara Ruas. Ou ainda, na criação de Sergio Faraco, Aldyr Garcia Schlee, Luis Fernando Verissimo, Moacyr Scliar, João Gilberto Noll, Luis Antonio de Assis Brasil.

Ora, desde pelo menos o final do século XIX, a literatura brasileira mostrou sinais de um diálogo com as literaturas vizinhas, sobretudo no caso da literatura produzida no Rio Grande do Sul. A princípio, esse diálogo se limitou a uma intertextualidade, reveladora de que os brasileiros liam obras de argentinos e uruguaios e delas se apropriavam, como é o caso de Martín Fierro, que ressoa em toda a gauchesca riograndense. Pouco a pouco, o intercâmbio foi se estreitando pelo encontro direto de alguns autores, pela correspondência entre eles e até mesmo pela tradução e a crítica recíproca, como no caso de Sergio Faraco e Mario Arregui (CHIAPPINI, 2011, p. 403).

No que se refere à literatura no Rio Grande do Sul, ela aponta ainda o surgimento de autores da zona italiana e alemã do estado, cujas escritas são tensionadas pela dupla existência, como é o caso de Jayme Paviani, Lya Luft e Charles Kiefer, para citar alguns por ela referidos.

Além desse reconhecimento da existência de um regionalismo étnico e com ele o reconhecimento de possiveis múltiplos sistemas culturais no sul do Brasil, situação também apontada por Léa Masina, Chiappini destaca ainda um novo fenômeno que vem ocorrendo com a literatura gaúcha nas últimas décadas, o qual poderá trazer outras mudanças e interferências. Para além do circuito tradicional de circulação, nos limites do estado, a literatura do Rio Grande do Sul, por diferentes aspectos, tem obtido edição e circulação de novos escritores no centro do país e já tem mostrado outras facetas.

Como procurei aqui demonstrar, Ligia Chiappini é uma das principais críticas brasileiras que tem se dedicado, ao longo de sua trajetória 
acadêmica, à literatura de fronteira do Cone Sul. Nesse longo percurso de pesquisa, acerca da literatura da região sul, que aqui busquei percorrer de modo sintético, destaca-se sua relevância para a abertura e a articulação de pesquisas realizadas em torno do tema, assim como algumas constantes em seu pensamento crítico.

Como creio ter deixado evidente, a pesquisadora inicia seus estudos da literatura regional do Rio Grande do Sul, considerando-a no conjunto do regionalismo no Brasil. Tendo como base, especialmente, o pensamento de Antonio Candido em torno de "Literatura e subdesenvolvimento" (1964/1972), que motivou a retomada dos estudos da literatura regional a partir dos anos setenta no Brasil, ao apontar que o regionalismo poderia ser manifestação literária de áreas subdesenvolvidas. Sustentada nessa premissa e tomando como parâmetro as iniciativas e as realizações do movimento modernista, em especial paulistano da década de 20 , é que Chiappini estuda a literatura do Rio Grande do Sul. Apesar de destacar o lugar singular de Simões Lopes Neto, ela acaba por ressaltar os limites do modelo de prosa regionalista no Rio Grande do Sul, no resultado de sua tese doutoral. O descritivismo, a personagem-tipo, o gaúcho herói, o foco narrativo externo ao mundo narrado, estratégias que marcavam essa ficção, coadunavam-se com a perspectiva do que Candido havia denominado de uma "consciência amena do atraso".

Porém, as pesquisas de Chiappini em torno dos regionalismos na Europa possibilitaram-lhe ampliar sua percepção acerca do "fôlego de gato" da literatura regional no Brasil e na América Latina como um todo. Percebendo o resurgimento do regionalismo nas literaturas dos países da Europa em momento de reorganização nacional, ela reconhece que a persistência dessa tendência ficcional não estaria apenas na condição de subdesenvolvimento da região e que tampouco sua qualidade estética deveria implicar uma superação do regional. Assim, afastando-se da ideia de superação do regional como prerrogativa de uma pretensa conquista de universalidade da obra, a pesquisadora passa a questionar, já nos anos noventa, conceitos como "super-regionalismo", de Candido, bem como a rever e a ampliar suas próprias leituras.

Para a pesquisadora, entender o regionalismo do sul requer, assim, já não só estudá-lo em relação ao modernismo brasileiro, mas, sobretudo, como um fenômeno da modernidade.

E então ela reconsidera, em parte, suas primeiras avaliações, entendendo que "o caso gaúcho é exemplar para se refletir sobre 
modernidades plurais", assim como para "repensar as relações entre nação, região e mundo, bem como localismos e cosmopolitismo, vanguarda e regionalismo" (CHIAPPINI, 2004, s/p.).

Partindo do conceito de comarca cultural, proposto por Rama, e articulando-o especialmente à circunscrição da América do Sul, Chiappini considera importante "superar a concepção estática dos territórios e nações para repensá-los não somente como processo e construção, mas, sobretudo, como projeto e utopia a construir pelo trabalho, [...]" (CHIAPPINI, 2011, p. 399). É assim, desde tal perspectiva epistemológica que, para a pesquisadora, outros brasis podem emergir.

No que tange à literatura produzida no Rio Grande do Sul, a pesquisadora reconhece, além da importância da gauchesca, também das "diversas faces da fronteira do sul", bem como a pertinência de estudos de outros textos cujas escritas são tensionadas pelo "duplo pertencimento" (CHIAPPINI, 2011, p. 410), como é o caso, por exemplo, dos produzidos nas zonas de colonização italiana e alemã do estado.

Seu trabalho de pesquisa em torno da produção ficcional do sul, contudo, como foi possível apreciar ao longo dessa retomada, segue no âmbito da literatura gauchesca. Assim, Chiappini delimita e orienta-se por um amplo arco temporal, a fim de abarcar um conjunto ficcional cujo centro é a figura do gaúcho, conforme evidencia a delimitação de seu repertório de leitura e seus trabalhos aqui resenhados.

O renovado caminho de pesquisa que Chiappini empreende, quer por meio de leituras comparatistas entre obras produzidas no universo hispânico e brasileiro, quer a partir da tradução e recepção no Brasil dessas obras, ou ainda pela produção crítica em torno do tema, trata das origens, dos intercâmbios, das semelhanças e diferenças do gênero gauchesco.

Sem se deter nas origens do gênero no universo hispânico, mas reconhecendo as origens da gauchesca enquanto projeto letrado de literatura nacional cuja base, para ela, foi uma imitação sistemática da linguagem e do estilo dos gaúchos, a pesquisadora opta por estudar as origens da gauchesca no Rio Grande do Sul em seus vínculos com a literatura platina.

Buscando conceber a história da literatura em sua condição transnacional, no século XX, a pesquisadora entende que essa pode ser compreendida em três momentos, como foi já mencionado anteriormente. Observo, assim, que Chiappini, à luz do que havia estabelecido Candido para as fases do regionalismo (1972) e buscando atualizá-las, estima a permanência e a transformação do gênero. Nesse sentido, ainda que aponte 
as diversas faces da literatura da fronteira, o trabalho de pesquisa de Chiappini atém-se ao estudo da gauchesca e de seu desdobramento enquanto pós-gauchesca.

Assim, os estudos da pesquisadora demonstram a revitalização dos estudos da literatura de fronteira do Rio Grande do Sul e a importância do estudo desse imaginário para o entendimento da cultura do Cone Sul. No entanto, o reconhecimento por parte da pesquisadora acerca de uma pluralidade da literatura da região, e a delimitação de seus estudos em torno de uma única tendência ficcional nas fronteiras do Cone Sul deixa em aberto duas lacunas fundamentais para a compreensão/construção do imaginário transfronteriço dessa região cultural: por um lado, ao manter seu interesse no campo da cultura letrada, promovendo os estudos do trânsito do tema da gauchesca entre a literatura e gêneros discursivos como o cinema, a música e a telenovela, pouco atenta para outras textualidades, como jogos, bailes, festividades, artesanatos e outras práticas populares que se inter-relacionam na constituição do imaginário dessa região cultural; por outro, a necessidade de desarticular a homogeneização a que foi submetida a produção ficcional da região. Limitação essa a que me referi no início desse artigo e que ainda prevalecem no âmbito de pesquisas e dos sistemas de ensino.

Para que sigamos descolonizando as histórias locais, o reconhecimento da coexistência de outras vertentes ficcionais no imaginário da região ou das diversas faces da literatura da fronteira, para usar a expressão de Chiappini, é uma primeira etapa. Outra indispensável, no entanto, é questionar a relação entre a construção de um sistema homogenizado e os fundamentos críticos sobre o qual ele foi construído.

Por isso, mediante um sintético percurso que busquei traçar de uma das principais linhas da crítica na América Latina e sua inter-relação com um uma região cultural mais delimitada, retomo agora o terceiro objetivo expresso anteriormente, qual seja, o de pensar a relação entre o objeto de pesquisa e a perspectiva crítica adotada. Por esse viés, para finalizar, quero ponderar acerca dos alcances e limites do imaginário crítico, bem como propor um caminho de leitura que possibilite maior visibilidade à pluralidade criativa na/da região.

Considero que o produtivo empenho por interpretar as relações da região e reconfigurá-la frente ao mapa das nações imaginadas não poderia ter caído na cilada da homogeneização do local em torno de essencialismos de uma identidade única, especialmente quando tratamos de pensar a 
literatura de fronteira do Cone Sul, no âmbito da América Latina, um espaço historicamente de múltiplos enfrentamentos culturais.

Quanto aos limites dos fundamentos críticos que se forjam pela iniciativa de diferentes intelectuais a partir dos anos sessenta, não posso deixar de ressaltar que, na base do paradigma transcultural, estão outros conceitos elementares do discurso crítico da modernidade, como o de mestiçagem, de sincretismo, de sistemas, de cultura letrada entre outros que levam a uma assimilação e invisibilização do outro.

Associando-me a uma das principais leitoras da obra de Rama, Mabel Moraña (1997) ${ }^{59}$, destaco que o pensador uruguaio criou um espaço de transitividade teórica em que conceitos, categorias e correntes de pensamento foram potencializados e refuncionalizados, oferecendo novos modos de entendimento da cultura latino-americana. Por isso, destaquei alguma das contribuições de Rama para a ampliação do cânone e a reconfiguração da historiografia na América Latina. Carências que, conforme sinalizei antes, em consonância com o pensamento do crítico, foram destacadas pelas palavras de Pizarro (1993) e atenuadas pelo trabalho realizado por diferentes pesquisadores. Contudo, um dos limites do paradigma da transculturação, conforme proposto pelo crítico uruguaio, está no fato de que seu foco tende a entender as relações culturais como um processo que culmina na criação de um terceiro objeto, intermediado pela cultura letrada.

Se em Transculturación narrativa en América Latina, a autoridade intelectual se impõe enquanto importante papel político e histórico para a revisão e a ampliação do cânone literário, é, sobretudo, em sua última obra - La ciudad letrada (1984) -, que Rama desdobra e justifica a posição assumida. Questionando a propriedade privada com que a letra foi tomada historicamente na América Latina e aspirando a que o ensino e a democracia desestabilizem esse poder, Rama apostava no papel do intelectual para incorporar e harmonizar as diversas culturas existentes. Assim, a soberania que a letra adquire no processo de transculturação literária na América Latina foi entendida por Rama como parte do trabalho do intelectual frente à modernidade.

Centrando-me nos estudos acerca do imaginário da comarca pampeana considero que tal perspectiva de leitura limita não só um estudo

\footnotetext{
${ }^{59}$ MORAÑA, Mabel. Ideologia de la transculturación. In: . Ángel Rama y los estudios latinoamericanos. Pittsburgh, Serie Criticas, 1997,137-146. MORAÑA, Mabel (org.) Nuevas perspectivas desde / sobre América Latina. 2a ed. Pittsburgh: Mabel Moraña Editora / IILI, 2002.
} 
de práticas populares, mas também da diversidade do imaginário que a criação literária da região promove.

Muitos pesquisadores, e aqui destaco o percurso de Chiappini, dedicados à leitura da ficção entre o sul do Brasil, o Uruguai e parte da Argentina, recorrendo a categorias crescidas no âmbito do pensamento latino-americanista, atuaram na configuração de uma unidade cultural para essa região. Destacar a relevância do empenho realizado por tais pesquisadores e o mérito da fundação de um espaço cultural que mobiliza um imaginário transnacional da região é necessário. No entanto, imprescindivel também é reconhecer que a perspectiva adotada, em certa sintonia com a tendência homogeneizadora do pensamento da modernidade, resulta na criação e na manutenção reiterada de um imaginário que se limita à literatura/cultura gauchesca.

Por isso percebo um descompasso: a relação entre o corpus e a crítica tem criado um consistente imaginário em torno de uma unidade cultural configurada como cultura gauchesca/ pós-gauchesca, no entanto, a literatura contemporânea produzida por escritores da região lida com um imaginário muito mais diversificado do que a produção crítica tem tratado.

A produção literária de escritores dessa região de fronteiras, conforme referencia o Acervo Literatura do Pampa, que venho organizando, aponta a existência de uma produção ficcional diversificada do imaginário dessa região cultural. Para citar alguns exemplos, destaco obras de escritores como Aldyr Garcia Schlee ${ }^{60}$, Mario Delgado Aparaín $(1949)^{61}$ e Jose Gabriel Ceballos $(1955)^{62}$.

A ficção produzida por esses escritores também fraturam a configuração das literaturas nacionais, ao inserirem-se em uma tradição ficcional de imaginar a região em uma condição transnacional. Suas narrativas fazem emergir dentro do território tradicionalmente vinculado à literatura gauchesca, um território outro: o das cidades de fronteiras e, com

\footnotetext{
${ }^{60}$ SCHLEE, Aldyr Garcia. Contos de verdades. Porto Alegre, Mercado Aberto: 2000. El dia em que el papa fué a Melo. Montivideo: Banda Oriental, 1991. Os limites do impossivel - Contos gardelianos. Porto Alegre, RS: ARdoTEmpo, 2009; Contos da vida dificil. Porto Alegre: Ar do Tempo, 2013, entre outros.

61 DELGADO APARAÍN, Mario. La balada de Johnny Sosa. Montevidéu: Banda oriental,1987, Cuentos completos. Argentina: Alfaguara, 2013, entre outras obras.

${ }^{62}$ CEBALlOS, Jose Gabriel. El Patrón del Chamamé. Concordia: Ediciones Rio de los Pájaros, 1998; Ivo, El imperador. Buenos Aires: Ediciones Sismurg, 2002; Fabulario de Buenavista. Buenos Aires: Ediciones Simurg, 2004; Vispera negra. Fundación Colegio del Rey: Alcalá de Henares, 2004, entre outras.
}

Caderno de Letras, nº 26, Jan-Jun - 2016 - ISSN 0102-9576 
elas, personagens e histórias outras. São ex-peões, changadores, embarcadiços, domésticas, prostitutas, estudantes, homossexuais, jogadores, travestis, proxenetas, músicos, radialistas, imigrantes. Mas esse espaço também está habitado por personagens que, frequentemente, assumem a condição autoral dos textos que narram. Recorrendo a repertórios culturais diversificados, suas narrativas expandem-se para além da historiografia e de vínculos com a ficção da região, uma vez que dialogam com outros discursos criativos, como o do cinema - dos filmes clássicos de Hollywoodianos aos melodramas mexicano e italiano - da música - entre a milonga, o chamamé, o bolero, o e o tango - e de histórias cotidianas -, com uma forte interlocução com gêneros orais, na obra dos três escritores aqui citados.

Por isso, o imaginário em torno dessa região, marcada tradicionalmente pela memória de uma cultura gauchesca e cujos símbolos da tradição em renovadas leituras são tomados como signos de resistência a uma pretensa identidade globalizada e desterritorializada, carece também de estudos de outras memórias inscritas no imaginário da literatura de fronteira. É um universo conflitivo, que povoa a criação de cidades como Jaguarão, Mosquitos, Las Cañas, Buena Vista, Rio Branco, Mello, Itaqui, Alegrete e, eventualmente, Montevidéu e Buenos Aires na obra dos escritores. Cidades com nomes inventados ou registrados todas estão vinculadas a uma referencialidade geográfica, que as situa nas fronteiras entre Brasil-Uruguai-Argentina. Essa orientação geocultural mobiliza significados fecundos na criação do espaço ficcional criado pelos escritores, uma vez que trazem consigo não só memórias inscritas na história da região, mas também o lugar a partir de onde os escritores leem, interpretam e criam seus universos simbólicos. Por isso a posição do lócus narrativo enquanto referencia fundacional de seus textos, frequentemente promovem semelhanças e continuidades e descontinuidades com memórias também relegadas em outras regiões do mundo. Na base desse conjunto de relações promovidas por suas narrativas, está o fato de que, afinal, o processo de modernização por que passa a região tem consequências e tratamentos semelhantes de exclusão, marginalização e ocultamento de histórias e memórias que também ocorreram/ocorrem em outras localidades. Por esse viés considero que a produção ficcional desses escritores leituras viabiliza uma abertura significativa para que se leia a região e sua inter-relação com o mundo em que vivemos.

Para finalizar, destaco que pensar a literatura de fronteira da região sul exigiu-me questionar também os pressupostos epistemológicos de sua 
leitura. Reflexão que me permitiu perceber a construção do paradigma transcultural como uma expressiva - e dominante - linha do pensamento crítico na América Latina, mas também destacar seus limites. Tal percurso ensinou-me, no entanto, a importância de postular modelos interpretativos a partir de especificidades de uma cultura.

Nesse sentido tanto a leitura que venho realizando da ficção dessa região do Cone Sul quanto à leitura crítica da crítica que a tem delimitado e interpretado exigiu-me buscar um caminho outro de leitura dentro da diversidade do pensamento desenvolvido na América Latina. Por isso opto por situar-me em outro caminho de leitura, que vem sendo desenvolvido a partir da América Latina, qual seja, o Pensamiento de frontera (MIGNOLO, 2000).

Assim, situando-me historicamente na tradição do pensamento crítico na América Latina, procuro realizar a leitura de obras ficcionais de uma região do Cone Sul a partir de um Pensamiento de frontera orientandome, para tanto, especialmente pelas propostas que vêm sendo desenvolvidas pelo grupo Modernidad/Colonialidad ${ }^{63}$.

Ciente de que o grupo tem como princípio organizativo a problemática da geopolítica do conhecimento $^{64}$, oriento-me pela construção de um pensamento crítico situado na América Latina para refletir sobre o imaginário de uma região de fronteiras do Cone Sul. Entendo que minha opção epistemológica mobiliza-me a ir além das

${ }^{63}$ Destaco que o primeiro artigo, que traça uma genealogia e um percurso do grupo, é desenvolvido por Arturo Escobar, no âmbito da proposta da temática do Congresso CEISAL - Amsterdam 2002, sob o titulo, "Mundos y conocimientos de otro modo - El programa de investigación de modernidad/colonialidad latinoamericano". Tal artigo foi publicado posteriormente em Tabula Rasa. Bogotá-Colombia, No. 1: 51-86, enero-diciembre de 2003. A genealogia e a história do grupo pode ser acompanhada em inúmeros outros trabalhos e entrevistas, por membros da rede de debate. Destaco aqui as obras El giro decolonial: reflexiones para una diversidad epistémica mas allá del capitalismo global (2007), compilada por Santiago Castro Gómez e Ramón Grosfóguel e Inflexión decolonial: fuentes, conceptos y cuestionamientos (2010), realizada por Eduardo Restrepo e Axel Rojas que são, especialmente, consideradas por mim.

${ }^{64}$ Como bem destacam dois pensadores dessa rede de pesquisadores, Ramón Grosfóguel e Santiago Castro Gómez, do mesmo modo que os Estudos Culturais e Pós-Coloniais, o grupo "modernidad/colonialidad reconoce el papel fundamental de las epistemes, pero les otorga um estatuto econômico, tal como le propone el análisis del sistema mundo". Ver: Prólogo: Giro decolonial, teoria critica y pensamiento heterárquico. In. GOSFÓGUEL, Ramón. El giro decolonial: Reflexiones para una diversidad epistémica más allá del capitalismo global. Bogotá: Siglo del Hombre editores; Universidad Central, Instituto de Estudios Sociales Contemporáneos y Pontificia Universidad Javeriana, Instituto Pensar, 2007, p. 16. 
"essências, particularidades e especificidades" da região e, diferentemente do pensamento latino-americanista que predominou nos anos setenta, pensar a partir de uma localização específica para dialogar horizontalmente com saberes múltiplos, internos e externos à América Latina.

Por isso, metodologicamente, empreendo dois movimentos para interpretar o imaginário da região cultural em que habito ${ }^{65}$ : inicialmente, entendendo a região de modo mais amplo, busco acompanhar, apreender e ponderar acerca do pensamento crítico na América Latina. E, assim, construindo e assumindo minha posição teórica enquanto lugar de enunciação $^{66}$, busco desenvolver minha interpretação do imaginário de uma região do Cone Sul, a partir de narrativas ficcionais de seus escritores.

Esclareço, assim, que trabalho, especialmente, com dois conceitos de fronteira: um que se constitui enquanto construção do pensamento crítico e proposta hermenêutica; e outro, partindo da concepção de espaço enquanto fundação político-cultural-simbólica, quer interpretar a ficção narrativa produzida entre uma região de fronteiras do Cone Sul - do Prata -, a fim de refletir acerca do imaginário ficcional e de sua relação com a construção dessa região. Mas este já é um trabalho a ser exposto em outro artigo.

\section{REFERÊNCIAS}

AGUIAR, Flávio. Ángel Rama e Antonio Candido - de um encontro feliz a uma nova realidade crítica na América Latina. In: AGUIAR, Flávio; RODRIGUES, Joana. Ángel Rama: um transculturador do futuro. Belo Horizonte: Ed. UFMG, 2013, p. 33-45.

CANDIDO, A. Literatura e subdesenvolvimento. In: FERNANDEZ MORENO, Cesar. América Latina em sua Literatura. Tradução Luis João Gaio. São Paulo: Perspectiva, 1979, p.343-362.

\footnotetext{
${ }^{65}$ Reitero, assim, que "habitar" não se limita a uma referência de ordem territorial, geográfica, em que me situo, mas, sobretudo, a uma delimitação do espaço epistêmico ou, mais precisamente, ao posicionamento de meu lócus de enunciação, fato que implica anunciar, como tenho feito desde o início deste trabalho, quem imagina, o quê imagina, a partir de onde e por que o faço.

${ }^{66}$ A referir-me a lócus de enunciação, explicito que o tomo na acepção do termo sugerido por Santiago Castro Gómez, como uma posicionalidad geo-ideológico-cultural. (CASTRO GÓMEZ/ E. MENDIETA, 1998). E nesse sentido relaciono-o a minha condição de "habitar" um lugar, conforme expliquei anteriormente.
} 
CARVALHAL, Tania Franco. Comunidades Inter-literárias e Relações entre Literaturas de Fronteira. In: ANTELO, Raúl (org.). Identidade e representação. Florianópolis: Pós-Graduação em Letras, UFSC, 1994, p. 93 102.

(org.) O discurso crítico na América Latina. Porto Alegre: IEL, São Leopoldo: UNISINOS, 1996.

. Dez anos de ABRALIC (1986-1996): elementos para sua história. Organon, vol. 10, n. 24. Porto Alegre: UFRGS, 1996.

. A tradição discursiva na América Latina e a prática comparatista. In: BITTENCOURT, Gilda Neves da Silva. Literatura Comparada: teoria e prática. Porto Alegre: Sagra, 1996, p. 198-207.

- Limiares culturais: as complexas relações sul/sul. Revista Iberoamericana LXIV. Nums. 182-183, Enero-Junio Pittsburg, USA, 1998, p. 97-106.

. O comparatismo nas fronteiras da crítica e a crítica de fronteiras. Caderno de Letras, vol.1, n.7, Universidade Federal de Pelotas, RS, 1999, p. $13-24$.

. Culturas, contextos, discursos - limiares críticos no comparativismo. Porto Alegre: UFRGS, 1999.

- Lugar e função da literatura comparada nos processos de integração cultural. Glauks Revista de Letras e Artes. Viçosa, Minas Gerais, v. 3, n. 4, 2000.

O próprio e o alheio - ensaios de literatura comparada. São Leopoldo: UNISINOS, 2003.

CASTRO-GÓMEZ, Santiago. La poscolonialidad explicada a los niños. Colombia: Editorial Universidad del Cauca. Instituto Pensar, Universidad Javeriana. Primera edición: noviembre de 2005. 
CASTRO-GÓMEZ, Santiago; GROSFOGUEL, Ramón. El giro decolonial: reflexiones para una diversidad epistémica más allá del capitalismo global (compiladores). Bogotá: Siglo del Hombre Editores; Universidad Central. Instituto Sociales Contemporáneos y Pontificia Universidad Javeriana, Instituto Pensar, 2007.

CASTRO-GÓMEZ, Santiago. Los vecindarios de la ciudad letrada. Variaciones filosóficas sobre un tema de Ángel Rama. In: MORAÑA, Mabel. Ángel Rama y los estudios latinoamericanos. Pittsburgh: Editora IILI, 1997. 123-133.

CÁSTRO-GOMEZ, Santiago y MENDIETA, Eduardo. Teorias sin disciplina (latinoamericanismo, poscolonialidad y globalización en debate). México: Miguel Ángel Porrúa, 1998. Acessivel em: <http://ensayo.rom.uga.edu/critica/teoria/castro〉.

CHIAPPINI, Ligia. Regionalismo e modernismo: o caso gaúcho. São Paulo: Ática, 1978.

. Literatura e história: da literatura na história e da história na literatura à literatura fazendo-sendo história. Anais do II Congresso da ABRALIC, Literatura e Memória Cultural. Vol I, 1990, p. 472-477.

. Velha praga? Regionalismos Literário Brasileiro. In: PIZARRO, Ana (org.) América Latina: Palavra, Literatura e Cultura. São Paulo: Memorial da América Latina/Campinas, 1994, p. 665-702.

. Do beco ao belo: dez teses sobre o regionalismo na literatura região, sertão, nação. In: Estudos Históricos: história e região. Rio de Janeiro: vol. 8, n. 15,1995 . p. 153-159.

No entretanto dos tempos: literatura e história em João Simões Lopes Neto. São Paulo: Martins Fontes, 1998.

De Fausto a Fausto: o gaúcho na ópera. IN: LOBO, Luiza (org.). Modernidad y modernización cultura y literatura en Latinoamérica. Equador, Quito: Abya Yala, 2000, p. 47-80.

. Martín Fierro e a cultura gaúcha do Brasil. In: Martín Fierro Edición Crítica. LOIS, Élida Lois e NUÑEZ, Ángel. Vol. 51 de Collection 
Archivos - ALLCA XX, California/USA: Editorial Fondo de Cultura Económica, 2001.

O modernismo no Rio Grande do Sul: revisitando uma pesquisa dos anos setenta. Revista Literatura e Sociedade. Departamento de Teoria Literária e Literatura Comparada. Faculdade de Filosofia, Letras e Ciências Humanas. Universidade de São Paulo, n. 7, 2003-2004, p. 256-265.

et al. Pampa e cultura: de Fierro a Netto. Porto Alegre: Editora da UFRGS/Instituto Estadual do Livro, 2004.

. Identidade Nacional - questão regional e cultural. In: KOHLHEPP, Gerd (org.). Brasil: modernização e globalização. Iberoamericana/Vermert, Madrid/Frankfurt am Main, 2005, p. 91-105.

CHIAPPINI, Ligia e MARTINS, Maria Helena (orgs.) Cone sul: fluxos, representações e percepç̃oes. São Paulo: Hucitec, 2006.

- Literatura e Fronteiras Culturais: Pampa e Amazônia. In: GALLINATI, Carla et al. Fronteiras da integração: dimensões culturais do Mercosul = Fronteiras de La integración: las dimensiones culturales del Mercosur. Porto Alegre: Território das Artes. 2011, p. 396-431.

- Texto Regionalismo(s) e Regionalidade(s) num mundo supostamente global, apresentado na ABRALIC, 2012. Email, no dia 18 de agosto de 2014.

CORONA, Ignácio. ?Vecinos distantes? Las agendas críticas pósmodernas en hispano America y en Brasil. Revista Iberoamericana. Vol. LXIV. Nums 182-183, Enero-Junio, 1998, p. 17-38.

GOULART, Catia. (org.). Fronteira Sul em Contos. Perspectivas de fronteira em audiolivro, volumes 1 e 2. Porto Alegre: Disc Press, 2009.

GOUlART, Catia. Perspectivas de Fronteira e Pensamento Latinoamericano. Anais do XIII Congresso Internacional de Literatura Comparada - ABRALIC- Campina Grande, Pernambuco, julho de 2013, 
volume $\quad 1, \quad$ N.2. $\quad$ Acessível em $<$ http://www.abralic.org.br/anais/?pagina $=10 \& a n o=2013$ >.

FICÇÃO, MEMÓRIA E IDENTIDADES NA AMÉRICA LATINA, UMA PERSPECTIVA DECOLONIAL - Anais do X Seminário Internacional de História da Literatura, v. 1, 2014. <ebooks.pucrs.br/edipucrs/Ebooks/Web/x-sihl>.

. A FRONTEIRA QUE HABITAMOS NA AMERICA LATINA Revista VOX, Porto Alegre: IEL \& CORAG, novembro de 2014, p. 28-31.

. POR UM PENSAMENTO DE FRONTEIRA. Anales del III Encuentro de las Ciencias Humanas y Tecnológicas para la integración de la América Latina y el Caribe - SIMPÓSIO 1 - Diálogos en el Conosur: Literatura, História e Fronteiras Sociais - Goiânia, Goiás, 7, 8 e 9 de maio de 2015, p. 05-21.

GOULART, Catia. Cuentos gardelianos: una biografia de la auséncia. Revista Les Ateliers Du Sal, n.7, 2015, 132-141. Acessivel em <https://lesateliersdusalfr.wordpress.com/numeros-precedents/deuxiemeepoque/numero-7/articles-numero-7/>.

GUERRERO, Jorge Carlos. La literatura en las cartografias regionales del Cono Sur. Frankfurt/Madrid: Iberoamericana \& Vervuet, 2010.

MIGNOLO, Walter D. Occidentalización, Imperialismo, Globalización: herencias coloniales y teorías poscoloniales. Revista Iberoamericana (p. 170171):1995.

MIGNOLO, Walter D. Histórias locais/ projetos globais: colonialidade, saberes subalternos e pensamento liminar. Belo Horizonte: UFMG, 2003.

A colonialidade de cabo a rabo: o hemisfério ocidental no horizonte conceitual da modernidade. Em: A colonialidade do saber: eurocentrismo e ciências sociais. Perspectivas latino-americanas. Buenos Aires: CLACSO, Consejo Latinoamericano de Ciencias Sociales Editorial/Editor, 2005. 
La Idea de América Latina - la herida colonial y la opción decolonial. Barcelona: Gedisa, 2007.

MORAÑA, Mabel. Ángel Rama y los estudios latinoamericanos. Pittsburgh: Editora IILI, 1997.

(org.) Nuevas perspectives desde / sobre América Latina. 2aed., Pittsburgh: Mabel Moraña Editora / IILI, 2002.

PICÓN SALAS. Mariano. De lo europeu a lo mestizo: las primeras formas de transculturación. In: . De la Conquista a La independencia - tres siglos de historia cultural hispanoamericana. México: Fondo de Cultura Económica, [1944], 1985, p. 84-85.

PIZARRO, Ana. El discurso literario y la noción de América Latina. In: 1º Seminário Latino-Americano de Literatura Comparada. Porto Alegre: UFRGS, 1986.

. Introdução. In: PIZARRO, Ana (org.) América Latina: Palavra, Literatura e Cultura - a situação colonial. Vol. 1. São Paulo: Memorial da América Latina; Campinas: UNICAMP, 1993, p. 19-37.

RAMA, Ángel. Transculturación narrativa en América Latina. México: Ed. Siglo XXI, 1982.

. Los gauchipoliticos rioplatenses, literatura y sociedad. Montevideo: Arca, 1998.

. La ciudad letrada. Montevideo: Arca, 1998.

RESTREPO, Eduardo; ROJAS, Axel. Inflexión decolonial: fuentes, conceptos y cuestionamientos. Colombia: Editorial Universidad del Cauca, 2010.

Recebido em: 02/07/2016

Aceito em: 22/07/2016 